\title{
Jugando con el
}

\section{arte moderno}

vol 14 / Jul. 2016 165-184 pp Recibido: 12-06-2016 - revisado 23-06-2016 - aceptado: 28-06-2016 


\section{PLAYING WITH MODERN ART}

\section{ABSTRACT}

Modern Art has directed an aesthetic look to children's life, appropriating their experimental processes.

The artistics avant-gardes camped in a pre-language territory, where all senses are preserved, ready to discover a world without names -the names cover the world; to dis-cover the word names must be set aside.

Because where language exists, there is no room for art: In order to give preference to perception, art must be unlinked from that which is linguistic, from codified communication, from the established system in which one creates and one receives statements.

In art, perception is an end in itself. Art is the procedure that seeks a reflective perception: it can only emerge when the communicative act is blocked and obstructed, and the perceptive act is prolonged.

Where can we find this state before language and from which art can emerge?

It is in the child who discovers a world full of nameless things.

Modern art is a child who plays, and who proposes, who was previously sentenced to be a spectator, to participate in the game.

\section{Keywords}

Modern Art, Childhood, Game, Perception, Education.

\section{RESUMEN}

El arte moderno es el único que ha sabido dirigir una mirada estética a la existencia infantil, apropiándose de sus procesos de experimentación.

Las vanguardias artísticas acamparon en un territorio previo al lenguaje, donde todos los sentidos perceptivos se conservan atentos, a la descubierta de un mundo sin nombres -los nombres cubren al mundo; para des-cubrir al mundo hay que apartar los nombres.

Porque donde hay lenguaje no cabe lugar para el arte: para poder privilegiar la percepción, el arte necesita desvincularse de lo lingüístico, de la comunicación codificada, del sistema establecido entre quien emite y quien recibe un comunicado; de quien, al mirar, simplemente reconoce.

En arte la percepción es un fin en sí mismo; arte es el procedimiento que busca la percepción reflexiva, y sólo surge cuando se bloquea y obstaculiza el acto comunicativo, cuando se prolonga el acto perceptivo.

¿Dónde encontrar ese estadio previo al lenguaje, en el que puede surgir el arte?

Está en el niño que descubre un mundo repleto de cosas sin nombre.

El arte moderno es un niño que juega, y que propone, a quien antes estaba condenado a ser espectador, a participar en el juego.

\section{Palabras Clave}

Arte moderno, infancia, juego, percepción, educación. 
Mariano Dolci, matemático y titiritero, responsable del Laboratorio di Animazione de las escuelas infantiles municipales de Reggio Emilia -conocido ahora como Laboratorio Gianni Rodari-, advierte: "Si no hay sorpresa, no hay proceso de conocimiento. El verdadero misterio que debemos resolver no está en lo desconocido, sino en lo conocido" (Dolci, 2006, p. 9).

Coincide con el lingüista Viktor Sklovsky, el primer crítico que supo ver y teorizar el naciente arte de vanguardia, quien señalaba que lo específico del arte es el procedimiento del extrañamiento, que rescata la percepción de la ceguera de una vida automatizada. En la rutina, se pierde la capacidad de ver lo conocido:

La gente que viene del mar se habitúa de tal modo al sonido de las olas que ya no las sienten. De la misma forma, raramente oímos las palabras que pronunciamos. Nos miramos pero no nos vemos. Nuestra percepción del mundo se ha desecado y disuelto, hasta el punto que se ha convertido en un puro y simple reconocer. (Sklovsky, 1970, p. 60)

Apenas reconocemos, ya dejamos de mirar, de escuchar, de percibir.

¿Qué veo? Si preguntáramos esto ante una obra moderna, la respuesta sólo podría ser: “Me veo mirar". Descubro que mirar, o escuchar, no tiene nada que ver con lo que yo hacía y suponía hasta ahora, cuando sólo pasaba la vista por encima de las cosas y la gente, para reconocerlas. Mirar una obra de arte moderno intensifica la percepción del espectador (Sklovsky, 1970), estrena la mirada.

La obra de arte moderna libera la atención de los sentidos. Es un objeto impertinente que vuelve nuestra percepción agudísima. La finalidad del arte es ser percibido, es hacer percibir. Así, convierte en anacrónica y cancela toda tradición perceptiva embotada y establecida.

¿Cual es la acción necesaria para mudar los sentidos? ¿Desde qué procesos es posible un arte nuevo, un mundo nuevo? Según Baudelaire (1976), se trataría de recuperar la mirada del niño que:

todo lo ve como novedad; está siempre embriagado. Nada se asemeja más a lo que llamamos inspiración que la alegría con la que el niño absorbe la forma y el color (...). El genio no es más que la infancia recobrada a voluntad, la infancia dotada ahora, para expresarse (...) de espíritu analítico. ( p. 690)

En nuestros días, el nexo entre arte moderno y pedagogía es más fuerte que nunca, porque las vanguardias históricas nos enseñaron a comprender, no sólo el arte hecho en nuestro tiempo, sino el arte de todos los tiempos y de todas las culturas, y en especial también el producido desde las vivencias de la infancia. El arte moderno, nuestro arte, es inclusivo: es el único que ha sabido dirigir una mirada estética a la existencia infantil, apropiándose de sus procesos de experimentación.

Las vanguardias atendieron a un momento previo al lenguaje, donde se conservan todos los sentidos abiertos. Allí donde hay lenguaje constituido, allí no puede haber arte; para primar 
la percepción, el arte necesita desvincularse de lo lingüístico, de la comunicación codificada, para poder así aparecer la percepción reflexiva. El objeto artístico surge cuando se bloquea y obstaculiza el acto comunicativo y se prolonga el acto perceptivo.

¿Cuál es el estadio previo al lenguaje? El del niño que descubre un mundo que aún no nombra. El arte moderno es un niño que juega y que propone, a quien antes no era sino espectador pasivo, a participar en el juego.

\section{EL JUEGO DE LA CREACIÓN, EL ARTE EN JUEGO}

Diez ejemplos del juego de la infancia. Diez obras modernas.

1 COLLAGE

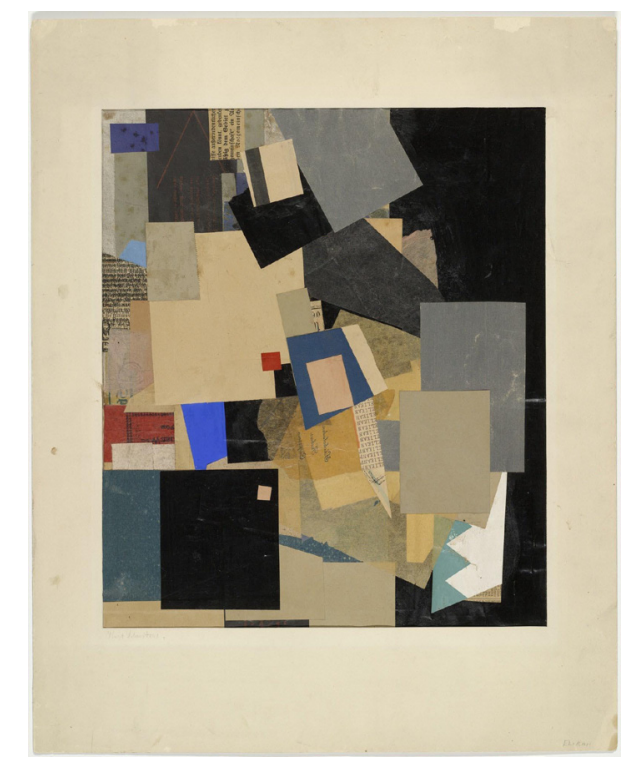

Figura 1. Kurt Schwitters, Sin título (Mz ELIKAN ELIKAN ELIKAN), 1925.

Collage de papeles de colores sobre cartulina $(43,5 \times 36,2 \mathrm{~cm})$. Museo de Arte Moderno de Nueva York.

(http://www.moma.org/collection/works/35548?locale=en)

Un cúmulo de recortes de papeles de color sobre una superficie; un collage. No parecen construir ninguna figuración, sino que se superponen y se combinan en composiciones anónimas. Hay autores modernos, como Kurt Schwitters, que no producen, no fabrican su obra, sino que la recogen, reúnen fragmentos: recortes de periódico, notas de compra, envoltorios, propaganda, entradas de espectáculos, fragmentos de manuscritos... Rescatados del desprecio del consumo, son redimidos en una nueva aparición, en la que destacan precisamente por las trazas de uso. Son materiales que no provienen del taller del artista, sino del desecho de la vida cotidiana, doméstica. Están al alcance de cualquier mirada capaz de percibir la atracción de un papel arrugado y lanzado al suelo, el brillo de un envoltorio de caramelo, la textura y de la intensidad de color de una etiqueta. 
Contemporánea de Schwitters es Rosa Agazzi, quien reúne, en 1922, las experiencias docentes que han dado lugar a su "museo didáctico" recogiendo los "tesoros" que los niños llevan consigo a la escuela, no para requisarlos y tirarlos a la basura, sino para convertirlos en privilegiado material pedagógico que preside el aula, y que podrían haber encontrado lugar en el Merzbau de Schwitters:

Los bolsillos de los niños regurgitan a veces cosas que no son bellas, no siempre limpias, incluso a menudo feas, sucias y peligrosas. Cajitas, clavos, botones, trozos de goma, cintas, cuerdas, tapones, huesos de fruta, se mezclan con canicas, roban el sitio al pañuelo. (Agazzi, 1973, p.29)

Es con ese material con el que Rosa Agazzi también "construye".

La técnica del ensamblaje, del collage, pertenece a las producciones infantiles. Los niños tienen la disgregación o destrucción y su complemento, el coleccionismo, como actividades de descubrimiento y de entrenamiento de la construcción imaginativa. En la reunión de los des-trozos surgen sus capacidades inventivas. Si se impusiera al niño la actividad del recorte de figuras, pronto quedaría enfocada su atención hacia el material sobrante, el desperdicio, que pasaría a ser en el niño -y en Schwitters y Agazzi- el material atractivo.

Los collages de Kurt Schwitters no se limitan a la superficie plana, pueden continuar su aglomeración sin límite, ocupando el volumen y el espacio, como hace la columna Merzbau. Iniciada en un rincón de su casa, el juego del collage invade el suelo y las paredes conquistando diferentes estancias, horadando el forjado y atravesando hasta el piso superior.

La mecánica de Schwitters en Merzbau coincide con la articulación a la que se refiere Josep Quetglas del desbordamiento del juego infantil:

Como los fantasmas atraviesan las paredes, el juego pasa a través de los espacios de la vida habitual, transformándolos, alterándolos (...). El juego subvierte el espacio que ocupa, y lo puede hacer con cualquiera. Sólo con una condición: los espacios tienen que ser habituales, no se tiene que estar en ellos como de visita. (14 de febrero de 2015, p.59).

En Merzbau todos los sentidos quedan convocados a través de los elementos perceptuales. Como la gruta de un animal o el nido de un pájaro que acumula metales brillantes, la columna de Merzbau está construida con desechos de metal, madera, materiales recogidos en la calle; y también de residuos de secreciones corporales (frascos de orina, uñas, cabellos de amigos), que guarda e inserta en las diversas capas de la estructura. Era una forma de interacción visual, cognitiva y física, con los objetos, las estructuras y los materiales en exposición. (Foster, Krauss, Bois, Buloch, 2006, pp. 210-211)

\section{PAPIER COLLÉ}

Una auténtica guitarra sostenida por unos brazos recortados en papel de periódico doblado cuelgan de un lienzo repleto de líneas rectas y curvas, que presienten un personaje. En la parte inferior del lienzo, sobre una mesita de bar, un diario doblado, una taza y una botella. Picasso 
compuso, o montó, o construyó, esta obra-instalación, "Construcción con tocador de guitarra", en 1913.

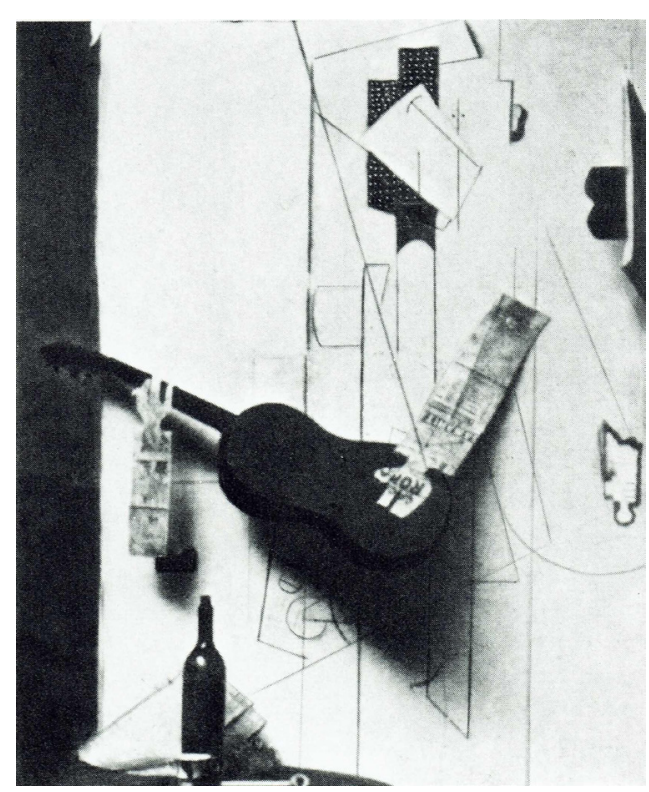

Figura 2. Pablo Picasso, Construcción con tocador de guitarra. Ensamblaje de recortes de papel y guitarra. París, 1913. Desaparecido. Publicado en Cahiers d'Art II/1950

Es una técnica que organiza con las tijeras y que ensambla realidad dibujada o recortada con objetos naturales. Más cercano al juego del niño que al de un artesano, más al de un chapuzas -bricoleur- que al de un carpintero, capaz de dominar y transformar un material. Quiere ver, directamente, con urgencia; no trata de crear; es un proceder del conocimiento.

Picasso juega con recortes de periódico, abriéndose así un campo de experimentación incomparable, que responde a sus talentos de bricoleur y a su estado de ánimo, pues los papeles recortados permiten y provocan todas las variaciones posibles de la imaginación. (Daix, 2002, p.96)

Picasso utiliza la técnica del papier collé, como "máquina de ver" que enfrenta la pintura con el objeto, el espacio real con el espacio representado, pintado. "Picasso proclamó su ruptura con todo un sistema de representación basado en parecer" (Foster et al., 2006, p. 112). Eliminando la frontera respetada hasta ahora por el artista académico. El juego del papier collé supera los límites que distinguen entre dos realidades distantes. La quietud hasta ahora del modelo a pintar se ha vuelto un escenario activo, movible y como tal frágil: No son tanto construcciones autónomas como disposiciones inestables de consistencia desigual, ambientaciones en las que integrar algunas piezas sólidas -la guitarra, por ejemplo- junto a mesas arrimadas o periódicos doblados fijados con chinchetas en la pared: obras capaces de sobrevivir únicamente en su fotografía. (Quetglas, 2001, p. 91) 
Completa ausencia de interés por todo lo que signifique expresión de uno mismo. John Cage (2007, p. 295)

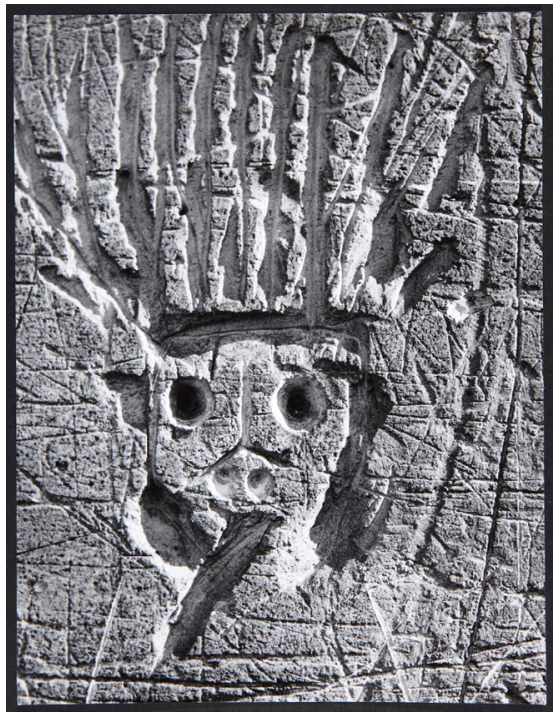

Figura 3. Brassaï, Grafitti. Série IX . Images primitives. Fotografía. París, 1945-50.

(http://www.museoreinasofia.es/sites/default/files/obras/AD06062.jpg)

El interés por las intervenciones murales anónimas que Brassaï descubre por las calles de París entre 1933 y 1960 es doble. Por una parte, porque son dibujos que carecen de sentido de composición "de lo bello". Al ser producciones plásticas infantiles no hay finalidades estéticas, ornamento cultural. Los garabatos y los grafitis carecen de técnica y lógica, según son los niños más jóvenes.

Según Picasso, los adultos imponen a los niños hacer dibujos de niños, de este modo sus dibujos no tienen nada natural. Pero en los dibujos callejeros de Brassaï, la mentalidad de los niños que los han realizado no ha sido todavía pervertida por la razón adulta.

Desdichadamente para la lógica, todo lo que construimos bajo ese rubro, "lógica", constituye tal simplificación respecto de los hechos y de los que realmente sucede, que debemos aprender a cuidarnos de ella. Esa es la función del arte actual: protegernos de todas esas reducciones lógicas que estamos tentados de aplicar a cada instante al fluir de los acontecimientos. (John Cage, 2007, p. 91)

El azar dirige el encuentro callejero con estas manifestaciones que Brassaï descubre mientras pasea por París. Las fotografía, redibuja y anota su dirección, para poder reencontrarlas y ver su transformación o desaparición, como si se tratara de una forma viva que habita en un espacio abierto a irrupciones colectivas. 


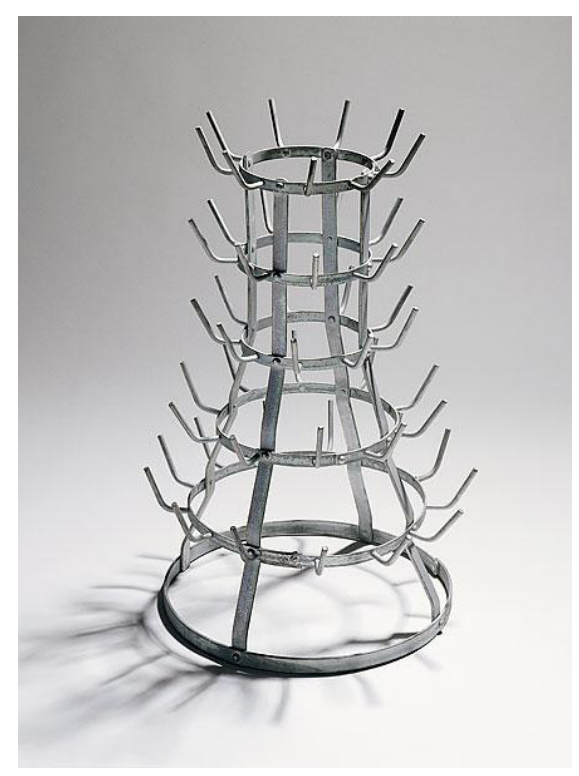

Figura 4. Marcel Duchamp, Porte-bouteilles.

Hierro galvanizado. Original perdido, realizado en 1914.

Réplica de Marcel Duchamp en 1964.

Centre George Pompidou, París.

(http://www.wikiart.org/en/marcel-duchamp/bottlerack-1914)

Duchamp toma un artículo de la vida cotidiana, una pieza de ferretería que adquiere en el Bazar de l'Hôtel-de-Ville, y lo hace desaparecer. Queda anulado su significado de uso, se origina una aparición nueva de aquel objeto. Desplaza el lenguaje y lo libera del reconocimiento de la vida práctica, útil; se ofrece a la vista extraño y nuevo, descubierto por primera vez. El proceso de producción del ready-made de Duchamp es el juego de representación, en el que, como en todo juego, dice Roger Caillois (2015), hay una conciencia de la realidad secundaria y de la vida corriente. Un proceso de descontextualización del objeto que pasa a ser una propuesta nueva durante el tiempo del juego.

Piaget describía el juego simbólico de un niño del mismo modo como un crítico de arte podría hablar del Porte-bouteilles de Duchamp, la rueda de bicicleta o el urinario. El juego simbólico aparece cuando el niño es capaz de separar el objeto de su significado. Cuando puede ver simultáneamente una lata de sardinas y un vagón de tren; una concha de sepia y un barco; un escoba y un caballo. El juego de ficción de ready-made hace del Porte-bouteilles una cosa distinta a la conocida. Se trata de ofrecer una situación inexistente, donde cada cual haga realidad su simulación. Con el juego, el niño, transforma el mundo exterior adaptándolo a sus necesidades. (Osterrieth, 1974) Pero no es un juego individual, sino colectivo: necesita la cooperación de otros para crear auténticas situaciones sociales con ese objeto (Vigostky, 2003). 
Son estrategias que combinaban el azar y la elección, lo arbitrario y lo dado. (...) que pusieron en duda de forma radical los conceptos convencionales de arte y artista por igual; eran 'obras de arte sin un artista que las haya hecho', señaló Duchamp en una ocasión. (Foster et al., 2006, p.127)

La propuesta de Duchamp no se detiene en el objeto, llega hasta la simulación de un personaje inexistente. "Adoptando el "je est un autre" (yo es otro) de Rimbaud, el desplazamiento de la subjetividad fue quizá el acto más radical de Duchamp" (Foster et al., 2006, p.159). Según Piaget, la flexibilidad de pensamiento adquirida a través de las situaciones de juego simbólico permite al niño tener el suficiente dominio de sí mismo como para poder llegar a representar un personaje diferente al que es él en la realidad cotidiana. El personaje otro de Duchamp es la mujer llamada Rrose Sélavy, fotografiada por Man Ray en 1920. Su nombre vagamente judío contiene los diferentes roles que puede poseer pronunciado en francés, desde "la vida es rosa" hasta "Eros es la vida": Rose, c'est la vie; Éros, c'est la vie.

La infancia como un mundo nuevo, y todo lo infantilmente fantástico, todo lo infantilmente directo, todo lo infantilmente figurativo contra las senilidades, contra el mundo de los adultos. Hugo Ball (1946, p. 101)

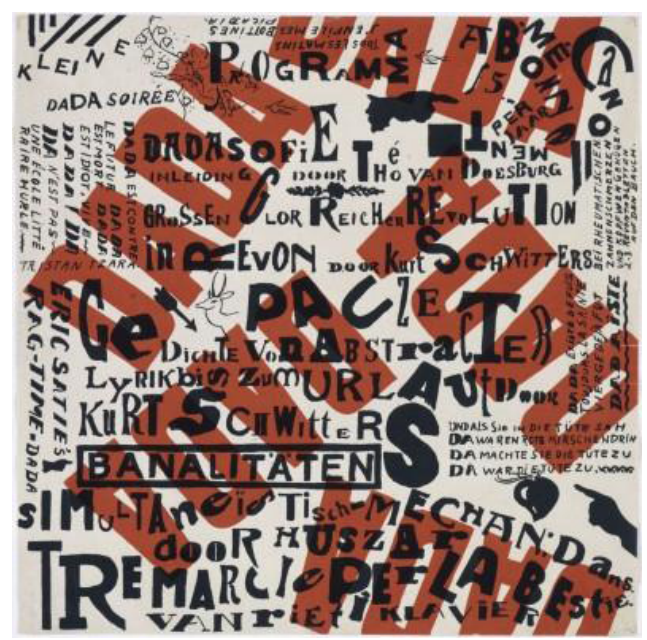

Figura 5. Dada, Kleine Dada Soirée.

Théo van Doesburg y Kurt Scwitters. 1922.

(https://commons.wikimedia.org/wiki/File:Theo van Doesburg kleine Dada soir\%C3\%A9e.jpg)

John Cage, músico y compositor, seguidor de Dada, describe la relación entre los adultos y los niños de un modo que se ajusta a la actitud dadaísta. Dice Cage que las personas suelen "mandar a los niños a jugar afuera, para que los adultos puedan seguir haciendo lo que están haciendo" (Cage, 2007, p. 13). 
¿Y si fueran los adultos que están a tu lado quienes se pusieran a jugar como niños, te interrumpieran e impidieran continuar con lo que haces? Esa interrupción, ese boicot a lo estipulado, es Dada. Dada libera la atención de los sentidos, con o sin permiso. Introduce el arte como un juego infructuoso, que no produce, que no perdura; que no es 'útil', que no hace, que no gana o pierde. Pero que impide que todo pueda continuar como antes.

Ese juego es el azar. El azar se rebela contra la repetición. Y nada, ni siquiera una tirada de dados, podrá jamás abolirlo. Cage procedía en sus composiciones como actuaban los dadaístas: "Tiene que haber varios acontecimientos que se desarrollen al mismo tiempo, o bien sucesivamente y sin ninguna relación entre sí. Si admitimos este punto de vista, salimos de la repetición y de la variación." (Cage, 2007, p. 43) Se trata de activar la facultad de la invención. En el Cabaret Voltaire, de Zürich, donde se refugiaron los dadaístas desde el 5 de febrero de 1916, las funciones eran un cúmulo de actividades, en porciones entrelazadas, superpuestas: de poesía, teatro, pintura, marionetas, etc., en la que no estaba determinado el final de una y el principio de otra.

"Recitaban manifiestos contradictorios, poemas en francés, alemán y ruso y salmodias casi africanas; también idearon conciertos con máquinas de escribir, timbales, rastrillos y tapaderas de ollas" (Foster et al., 2006, p.136).

En Dada no hay ningún bloqueo por unos valores, ni esclavitud a un juicio, ni autor que dirija los sentidos del público. Rompen tanto el papel directivo del autor como el papel pasivo y sometido del espectador, que va a ver qué le enseña quien. El espectador tiene que ser, él también, autor de la obra, y, puesto que la obra queda disuelta en el mismo gesto de hacerse, autor de su propia vida, única cosa que prosigue y se transforma.

"Los dadaístas se comprometieron a atacar todas las normas, incluso las incipientes suyas ("El Dadaísmo es antidadaísta" fue uno de sus estribillos favoritos), y así lo hicieron, en Zúrich, mediante extravagantes representaciones y publicaciones" (Foster et al., 2006, p.135).

El juego debe tener un resultado incierto. Según Roger Caillois, su desarrollo no puede estar predeterminado, y la duda sobre el resultado se tiene que prolongar hasta el final, puesto que, de no ser así, perdería la atracción y habría dejado de ser juego. Y debe ser una actividad improductiva. El juego no crea ninguna riqueza, ninguna obra. Ni siquiera crea y cualifica a su autor. Al final de la partida, todo puede y tiene que volver a empezar desde el mismo punto.

Los críticos que en general relacionan mis actividades con el dadaísmo no se engañan. Pero he podido observar que en 1920 el movimiento Dada tenía una necesidad mucho más virulenta de cortar con todo lo hecho, más necesidad de vacío, que en 1950. (Cage, 2007, p. 218)

Los dadaístas reaccionaron contra una sociedad -contra su arte y sus valores- que fueron incapaces de evitar la barbarie de la Primera Guerra Mundial. "El Dadaísmo apuntó directamente a la cultura burguesa, a la que culpaba de la carnicería de la guerra" (Foster et al., 2006, p.135). Ese mundo debía acabarse -debía ser acabado. 
Una de las producciones más cercana al proceso de creación infantil es la action painting. Su centro de interés es el gesto o movimiento de pintar, no su resultado, el inevitable registro pintado. La obra es su proceder, como sucede también en las Antropométries de Yves Klein.

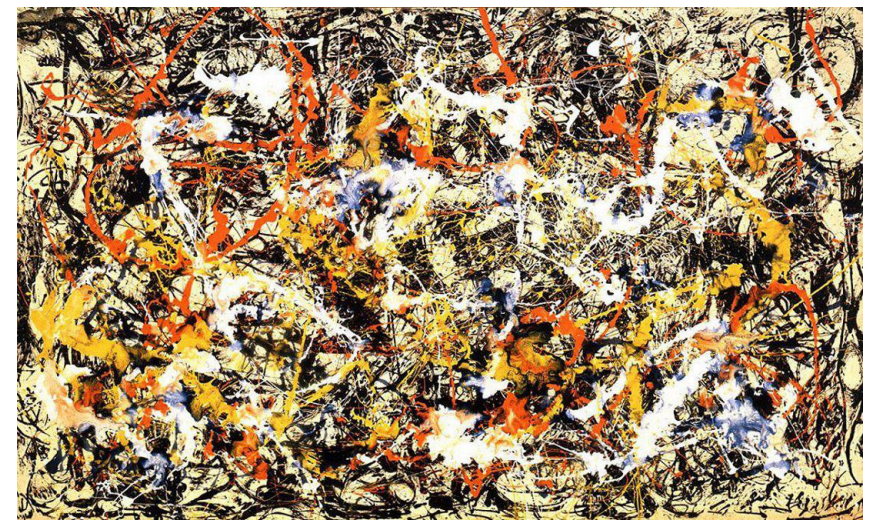

Figura 6. Jackson Pollock, Convergence.

Óleo sobre tela, 1952, $270 \times 525 \mathrm{~cm}$

(http://2.bp.blogspot.com/)

El dripping funciona como el garabateo infantil, en la que el niño y el pintor son conducidos por el gesto repetitivo e hipnótico. El contacto con la materia, verla caer, gotear, derramarse, brillar, manchar: necesidad fundamental del tacto visual.

Rudolf Arnheim describe este mismo movimiento oscilante de la etapa en que el niño emborrona el papel y observa lo que en él aparece,

En la etapa del garabato, la mano del niño oscila rítmicamente por algún tiempo a modo de péndulo sin levantar la mano del papel. A medida que se desarrolla en él la forma visualmente controlada, comienza a trazar elementos claramente separados. (Arnheim, 1977, p. 171)

Se podría pensar que es un proceso que sólo capacita a quien lo realiza, que el espectador sólo constata en la observación de la obra la recreación de quien lo ha hecho. No es sólo así. Quien atiende con agudeza a los restos de manchas de pintura, de hilillos y salpicones sobre la tela, va dotándose gradualmente de la misma destreza de quien lo hizo, sumándose a ese juego gestual e improvisado del niño y de Pollock.

Mirar una obra de Jackson Pollock es intervenir en los gestos. Descubrir que el azar del espectador, que se mueve errante sobre la tela sin encontrar el centro donde poner atención, es el mismo azar de la técnica errante de su autor. Sus ojos repiten los movimientos de balanceo de una punta a otra del soporte que Pollock. Las telas de Pollock, de grandes dimensiones, impiden al espectador verlas de un solo vistazo, le obligan a ir y venir de una punta a otra. 
Pero al detenernos en una zona cualquiera del cuadro, y mirar sin prisas, atentos al hecho de percibir, empezaremos a ver que esa primera maraña indescriptible de manchas y salpicones de pintura empieza a destramarse, y distinguimos nerviosidades, profundidades, características específicas en unas y en otras. Se descubre que a cada impulso impremeditado le corresponde una intensidad nerviosa de pigmento.

Continuamos mirando, descubriendo poco a poco que no sólo hay una distinta posición en superficie, sino también en profundidad. Los recorridos de la pintura blanca pasan en un estrato distinto al de los salpicones rojos, o los amarillos. La tela se muestra simultáneamente como una superficie plana y como un fondo con profundidad.

Los ojos del espectador, nuestros ojos, han ido adquiriendo gradualmente una finura perceptiva que antes no tenían, una capacidad antes desconocida. La obra ofrece al espectador una mirada nueva, que puede registrar su forma y participar en ella. Ahora, en cualquier momento, ante la reclamación del niño, podemos participar. Se nos han desvelado las reglas del juego.

Una región en la que nada aparece como presentación o concepto, y en la que todo se da a través de imágenes y de signos. (Argan, 1991, p. 299)

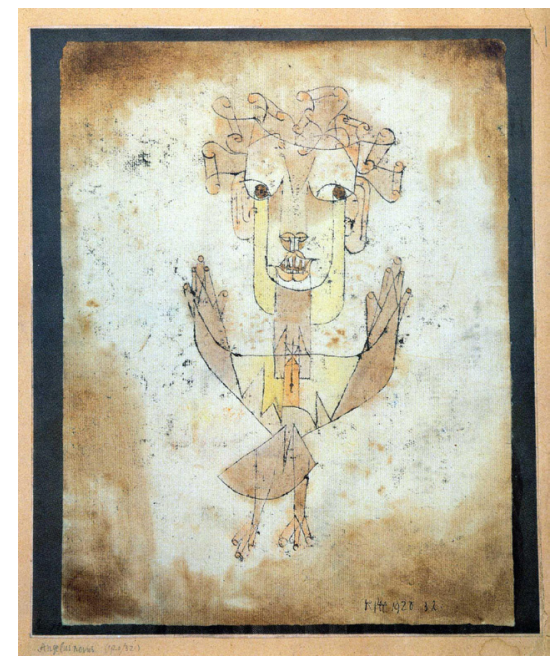

Figura7. Paul Klee, Angelus Novus.

Tinta china, tiza de colores y aguada marrón, 1920, 31,8 x 24,2 cm (https://commons.wikimedia.org/wiki/File:Klee, Angelus novus.png)

En un escrito de Klee (1920), titulado Credo Creativo señala que el niño -el primitivo y el enfermo mental- tienen una posición especial como habitantes de un mundo "intermedio" que existe entre los mundos que perciben nuestros sentidos (...) todos siguen teniendo -o han descubierto- el poder de ver. 
Hacer visible algo que antes no existía es una experiencia que se conoce bien en la infancia.

Los primeros garabatos del niño no tienen por destino representar nada, sino más bien presentar; esto es, implican la excitante experiencia de realizar algo que antes no existía. Este interés en el producto visible por sí mismo (...) está presente en toda obra de arte. (Arnheim, 1977, p. 30).

"El arte no representa lo visible; más bien, lo hace visible". (Klee, 1920). La finalidad de la obra de arte es la de dar la sensación de la visión, de la percepción, no de reconocer objetos o contenidos. Este propósito es compartido por la infancia y por Paul Klee. No se trata de representar, sino de presentar, de visualizar.

Se representa algo que ya tiene una forma (...) en la imaginación del artista; se visualiza algo que, antes de ser visualizado, carecía de una existencia fenoménica. (...) Para Klee, la operación artística es similar a la del investigador que, utilizando determinados medios técnicos, hace visibles (pero no representa) los microorganismos que indudablemente existen, pero que de otro modo no serían visibles. (Argan,1911, p. 299)

Klee reduce el mundo como hace el niño mediante el dibujo, con recursos inventados e intuitivos. El niño se educa a sí mismo. Se ofrece y descubre las herramientas necesarias de conocimiento del mundo. Para ello es fundamental la actividad gráfica de la infancia, que refleja los primeros actos de una autoeducación estética. Educación estética que, para Klee, es el eje del sistema educativo de una sociedad democrática.

Para Klee, como para Kandisky, el arte (..) tiene una determinada función formativa o educativa. Se diría que toda su obra, incluso sus aspectos más lúdicos o de juego más evidentes, está inspirada en la idea de la educación estética como educación para la libertad (...). (Argan,1911, p. 299)

En la primera etapa, cuando el niño aún no sabe leer ni escribir, experimenta con lo que le llega a las manos. Manipula los materiales con los que hace grafismos, aparentemente sin sentido, obteniendo sus primeros garabatos. Es el mismo estadio en donde se quedan las obra de Klee, en el impulso o el motivo.

La segunda etapa ya conoce las técnicas, sólo plasma y experimenta sobre la primera impresión unas formas que asemejen las cosas y objetos que tiene a su alrededor.

"Los signos corresponden a determinados significados (es decir, los lenguajes representativos, cuyas formas están lógicamente vinculadas a los objetos) son signos apagados, que va del hombre sin pasar por la intermediación del objeto o de la naturaleza" (Argan,1911, p. 295). 
En la tela flotan formas que no responden a ningún objeto preciso. Son todas ellas figuras explosivas, pinceladas vibrantes.

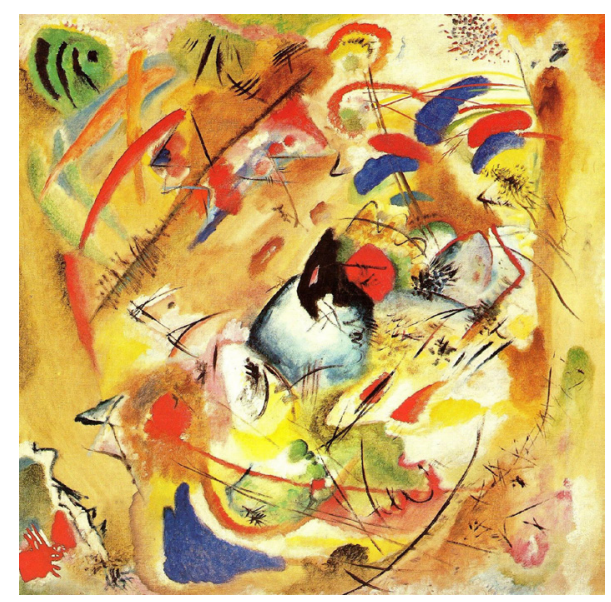

Figura 8. Wassily Kandinsky, Fantasía improvisada.

Óleo sobre tela, 1913,(130,7 x 130,7 cm), Staatsgalerie Moderner Kunst, Munich

(https://en.wikipedia.org/wiki/Wassily_Kandinsky\#/media/File:Vassily Kandinsky, 1913 _ Composition 6.jpg)

Kandinsky mostró interés en las manifestaciones plásticas de los niños. Trató de colocarse en una situación previa al lenguaje y al conocimiento racional.

Parece que vuelve al primer estadio del grafismo infantil, a la fase que los psicólogos llaman "de los garabatos" (...), que se identifica con la condición de tabula rasa de la primera infancia. Evidentemente, Kandinsky quiere volver al estadio inicial de la pura intencionalidad o voluntad expresiva que aún no se apoya en ninguna experiencia visual y lingüística. Las "Improvisaciones" (el título mismo es ya indicativo) se presentan como movimientos agregados de signos sin soporte estructural u orden aparente. En ese mismo dibujo hay signos de distintos orígenes que es imposible combinar en un orden morfológico y sintácticamente coherente: puntos, comas, zigzags, curvas, rectas, manchas, nubes de color. (Argan,1911, p. 296-297)

Así, en 1910, Kandinsky "olvida" su oficio de pintor figurativo y se pone a pintar como un niño de 4 años. Como si los ojos se abrieran por primera vez. Cómo hace un niño que todavía no ha aprendido a distinguir objetos, a separar entre su cuerpo y el mundo, a separar unas cosas de las otras, y sus ojos y su piel están abiertos y maravillados por la impresión que reciben de luces, colores, movimientos, temperaturas. Las formas sobre el cuadro son fragmentarias, descoordinadas, no son objetos con un margen definido, sino quietudes o movimientos, agudos o redondos, filiformes o expandidos.

Una impresión que no puede ser dicha en palabras, sólo pintada, como un sabor no puede ser dicho en palabras. 
En su texto Sobre lo espiritual en el arte, de 1910, Kandinsky explica que toda forma tiene un contenido propio, intrínseco, y no se trata de un contenido objetivo o de conocimiento (como aquel mediante el cual se conoce y se representa el espacio a través de formas geométricas) sino de un contenido-fuerza, una capacidad de actuar en cuanto estímulo psicológico. (Argan,1911, p. 296)

Kandisnky recuerda que, un día, al volver a casa después de estar trabajando, abstraído por el trabajo que acababa de concluir, cuando de golpe vio un cuadro de una belleza indescriptible, de una gran fuerza interior. Después del primer desconcierto se dirigió rápidamente hacia aquel cuadro misterioso en el cual no veía nada más que formas y colores y que el tema le resultaba incomprensible. De golpe entendió la clave del enigma: se trataba de uno de sus cuadros apoyado de lado en la pared. El día siguiente intentó revivir la impresión del día anterior ante el cuadro, pero sólo lo consiguió a medias. Reconocía constantemente los objetos. Pero ya estaba seguro de una cosa: la presencia del objeto perjudicaba su cuadro.

He descubierto la punto cero de las formas, y he salido del círculo vicioso en el que están encerrados el artista y las formas de la naturaleza.

(Malevich, citado en Daix, 2002, p. 156)

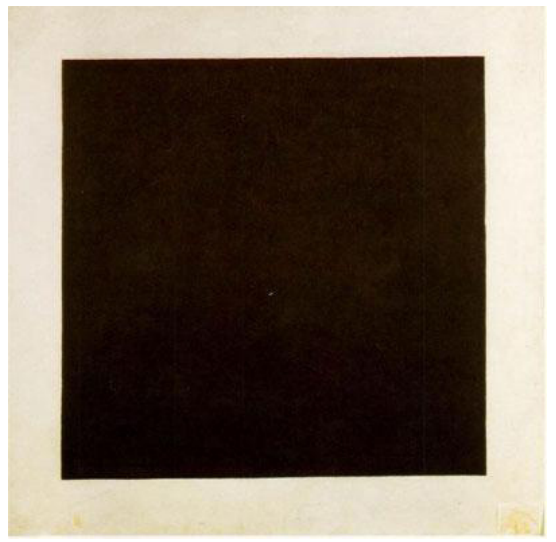

Figura 9. Kazimir Severimovitx Malevich, Cuadrado negro sobre fondo blanco.

Óleo sobre tela, 1915 (79,5 x 79,5cm). Galería Tretiacov, Moscú

(https://commons.wikimedia.org/wiki/File:Malevich.black-square.jpg)

Antes, ver un cuadro consistía en reconocer la convención representada sobre la tela, comprender su argumento. Se valoraba la justa correspondencia entre el argumento y la representación visual. El espectador reconocía en el cuadro alguna cosa anteriormente vista o experimentada, y el autor se servía de ese reconocimiento para transmitir un mensaje, una idea o un sentimiento, por medio de un código formal también experimentado por el espectador. Se decía que un cuadro era una ventana al mundo.

Pero entre los últimos años del siglo XIX y los tiempos de la Gran Guerra y la Revolución Rusa, una serie de autores, pintores, escritores, músicos y arquitectos quisieron acabar con esta forma 
de arte, que existía para que el autor explicara lo que el espectador obediente debía aprender. La revuelta de Malevich forma parte de la revuelta contra la obediencia al viejo mundo. "Malevich se encarga de la formación intelectual rigurosa de las generaciones que habrán de construir el socialismo" (Argan, 1997, p. 303).

Kazimir Malevich decide borrar del cuadro todo argumento, figura o referencia que ya forme parte del mundo, para encontrar lo que no forma parte del mundo, sino sólo de la pura pintura.

¿Hay árboles en el mundo? Sí. Fuera árboles del cuadro. ¿Hay vacas, flores, sol y luna, estrellas, hombres y mujeres en el mundo? Pues fuera vacas, flores, sol y luna, estrellas, hombres y mujeres del cuadro. ¿Se cuentan batallas, historias, hay sentimientos? Fuera contar nada, fuera sentimientos, sin miedo y sin alegría.

Hay que des-cubrir en la pintura lo que sólo se puede encontrar y existir en el cuadro. La pintura no representa. La pintura presenta, el cuadro es.

Malevich hace como el niño que se aísla en su juego, que se sitúa en un tiempo y un espacio concretos (Huizinga, 1938). Separado de la vida corriente, de la cotidianidad, está inmerso en una ocupación que debe ser realizada dentro de uno límites precisos, un tiempo y un espacio diferente. (Caillois, 2015)

Sus reglas son llegar a la presencia pura de la pintura, desposeyendo de la tela todo lo que pertenezca o se encuentre fuera del juego, fuera del cuadro. Llega así a pintar en 1915 el Cuadrado negro sobre fondo blanco. Una tela cuadrada de poco más de un metro de lado, que se conserva en el museo del Hermitage en San Petersburgo, donde el espectador se encuentra ante lo que "sólo" es pintura. Un cuadrado negro de determinadas dimensiones sobre un fondo blanco de determinadas dimensiones.

¿Es abstracto? Sí, porque se ha abstraído del mundo. ¿Es concreto? Sí, porque es presencia pura de esta pintura.

Malevich denominó "suprematistas" a la serie de cuadros iniciada con el cuadrado negro, indicando que se trataba de la supremacía del puro sentimiento pictórico. Cada una de las obras suprematistas tiene unas calidades pictóricas que dependen de los pesos ópticos, medidas y coloraciones de las formas. Situadas sobre la superficie del cuadro, flotan y viven como las reglas del juego infantil en Callois y Huizinga: en un nuevo tiempo, en un espacio diferente y propio; en un nuevo ambiente, un nuevo mundo, sin más objetos que los de la pintura, que los del juego.

\section{CONSTRUIR}

El Lissitzky y los constructivistas involucran al espectador, al público que mira, alterando sus costumbres y rompiendo los límites de la obra pictórica, la escultura, o la arquitectura. El arte moderno no sólo ha dado otros materiales, otra actividad y otra posición respecto al mundo, a la obra y al autor: ha fabricado, además, otro espectador; otra tarea para el espectador. (Quetglas, 2001) 


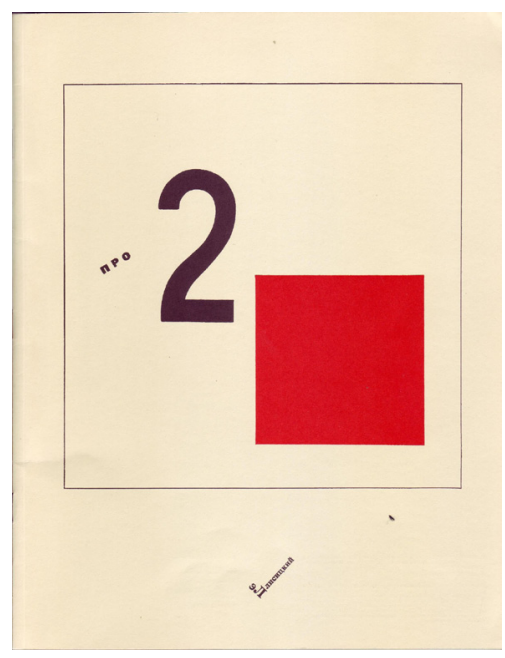

Figura 10. El Lissitzky, Cuento de los dos cuadrados. Historia Suprematista de dos cuadrados en seis construcciones. Cuaderno de doce páginas, 1922

(https://commons.wikimedia.org/wiki/Category:About_2_Squares\#/media/File:ElLissitsky-Suprem-cover.jpg)

La obra de arte ya no es una forma homogénea, sino un montaje abierto de piezas, que muestra sus ensambles, invitando al espectador a intervenir en su construcción.

\begin{abstract}
Las formas pueden salir de la superficie de la tela y demostrar su realidad corporal, como las obras de Tatlin, de Lissitzky o del mismo Malevich. Las formas apoyadas físicamente sobre la superficie del cuadro se lanzan directamente para afectar el ambiente reservado hasta aquel momento al espectador, como construcción efectiva, no alusiva, de un nuevo mundo a este lado del espejo.
\end{abstract}

(Quetglas, 2001, p.89)

El arte tiene una función en el desarrollo de la nueva sociedad, potenciando las facultades perceptivas e inventivas. De esa creación de un mundo nuevo forma parte el niño, para quien Lissitzky construye en 1922 un cuento que da el salto de la lectura pasiva a la lectura activa: Cuento de los dos cuadrados. Historia Suprematista de dos cuadrados en seis construcciones.

La mirada del lector, niño o adulto, se pasea por encima de la hoja libremente, ve letras, que puede leer o, "simplemente", ver como formas, incluso letras convertidas en personajes. Un gran impacto visual lo deja hipnotizado y empieza, sin desconfianza a adentrarse en las página que están en movimiento. El Lissitzky hace atender a unas palabras que ya están dibujando aquello a lo que remitirían en otro orden.

El mismo cuento nos hará más capaces, nos enseñará algo que, a partir de entonces, nos hará diferentes. Y lo aprenderemos de forma activa, mediante el juego, que es una actividad que implica acción y participacióń activa: explorar, interpretar, moverse, construir. 
En el un cuento, un cuadrado negro y uno rojo parecen cooperar para dispersar el caos y establecer un nuevo orden. Lissitzky utiliza cuatro tipos de lenguaje: letras (en cirílico), números, formas y colores. La historia empieza interpelándonos: "NO LEAS", y una dinámica línea en zigzag, que ocupa toda la página, lleva al nuevo comportamiento: “Coge papel y pliégalo. Coge bastones y barras y píntalas. Coge piezas y construye."

En 1928, Lissitzky lleva al límite su activación del espectador, realizando la Sala de demostración, en Hannover, una instalación donde las paredes estaban revestidas de cajones, armarios y estanterías, con pinturas y dibujos encerrados dentro. Cuando el visitante abría los armarios encontraba los cuadros entre los que podía elegir cual o cuales colgaba de las estanterías. Lo que había sido el espacio contemplativo e inmóvil del museo se había convertido en un archivo de trabajo, análogo a aquella caja de herramientas en forma de colección nunca acabada de citas que Walter Benjamin -otro atento observador de los juguetes y la infancia- proponía al antiguo lector, para que, como un jugador de naipes, estableciera su juego.

\section{JUGANDO CON EL ARTE MODERNO}

El juego ocurre en un tiempo propio, diferenciado, que empieza y acaba; y en un espacio propio, elástico y efímero, condición y resultado, que permite y produce el juego.

El niño juega siempre en un aquí y ahora; no le interesa el resultado o producto final sino la conducta, la actividad. Es más importante el medio que el resultado, porque, aun cuando lo tuviera presente, éste puede ir variando a lo largo del juego, para que encaje con otros medios que se van descubriendo a medida que transcurre el juego (Huizinga, 2004). Una de las características del juego, según Huyzinga en Homo Ludens (1938) y Roger Caillois en Les jeux et les hommes (1957), es que no se puede obligar a jugar; jugar es una opción directamente personal, voluntaria e impremeditada. Por sí mismo, el juego no obliga a nada.

El músico John Cage reconoce como material de su oficio la misma regla del juego libre de Huizinga y Caillois:

Creo que la música - por lo menos tal como yo la entiendo- no impone nada. Puede tener por efecto modificar nuestra manera de ver, hacernos mirar nuestro entorno como si fuese arte. Pero eso no es un objetivo. iLos sonidos no tienen propósito! Simplemente son. Viven. La música consiste en esa vida de los sonidos, en esa participación de los sonidos en la vida, que puede convertirse-pero no voluntariamente-en una participación en la vida de los sonidos. Por sí misma, la música no obliga a nada. (Cage, 2007, p. 98) 


\section{Bibliografía}

Agazzi, R. (1973). Come intendo il museo didattico nell'educazione dell'infancia e della fanciullezza. Brescia: La Scuola Editrice.

Argan, C. (1991). El arte moderno. Madrid: Akal.

Arnheim, R. (1977). Arte y percepción visual. Psicología de la visión creadora. Buenos Aires: Editorial Universitaria de Buenos Aires.

Ball, H. (1946). Die Flucht aus der Zeit. Lucerna: Josef Stocker.

Baudelaire, C. (1976). Le Peintre de la vie moderne. En C. Baudelaire, CEuvres complètes (pp. 683-725). Paris: Gallimard.

Daix, P. (2002). Historia cultural del arte moderno: El siglo XX. Madrid: Cátedra.

Dolci, M. (2006). Preguntes de teatre i art a l'escola. Infància: educar de 0 a 6 anys, 153, 6-9.

Cage, J. (2007). Para los pájaros. México: Alias.

Caillois, R. (2015). Los juegos y los hombres. La máscara y el vértigo. Madrid: Fondo de Cultura Económica de España.

Foster, H.; Krauss, R.; Bois, Y.-A.; Buloch, B. H. D. (2006). Arte desde 1900. Modernidad, antimodernidad, posmodernidad. Madrid: Akal.

Huizinga J. (2004). Homo ludens. Alianza, Madrid.

Osterrieth, P. (1974). Psicología infantil. Madrid: Morata.

Quetglas, J. (2001). Pasado a limpio, II. Valencia: Pre-Textos.

Quetglas, J. (15 de febrero de 2015). Espais de joc. Mallorca: AraBalears.

Sklovsky, V. (1970). El arte como artificio. En T. Todorov, Teoría de la literatura de los formalistas rusos (pp. 55-70). México: Siglo XXI.

Vigotsky, L. (2003). La imaginación y el arte en la infancia. Madrid: Akal. 
